\title{
1H-1,2,3-Triazole Tethered Nitroimidazole-Isatin Conjugates: Synthesis, Docking, and Anti-Proliferative Evaluation against Breast Cancer
}

Sumit Kumar, ${ }^{\dagger}$ Sourav Taru Saha, ${ }^{\ddagger}$ Liang Gu, ${ }^{\ddagger}$ Gabriella Palma, ${ }^{\ddagger}$ Shanen Perumal, ${ }^{\ddagger}$ Ashona Singh-Pillay, ${ }^{\S}$ Parvesh Singh, ${ }^{\S}$ Amit Anand," Mandeep Kaur, and Vipan Kumar*, ${ }^{*}+0$

${ }^{\dagger}$ Department of Chemistry, Guru Nanak Dev University, Amritsar 143005, India

${ }^{\ddagger}$ School of Molecular and Cell Biology, University of the Witwatersrand, Private Bag 3, Wits, 2050 Johannesburg, South Africa

${ }^{\S}$ School of Chemistry and Physics, University of KwaZulu Natal, P/Bag X54001, Westville, Durban 4000, South Africa

"Department of Chemistry, Khalsa College, Amritsar 143005, India

\section{Supporting Information}

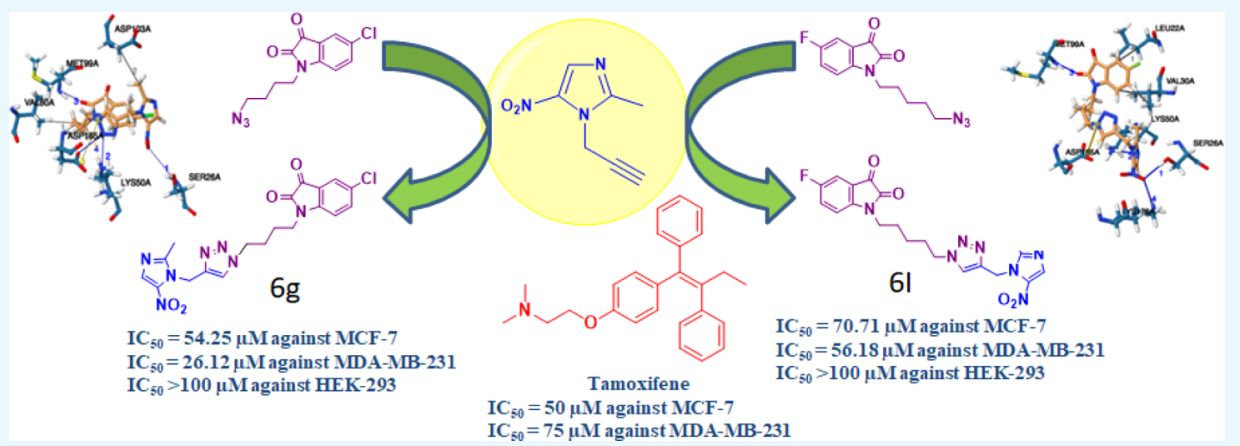

ABSTRACT: $1 H-1,2,3-$ Triazole tethered imidazole-isatin and imidazole-isatin-thiosemicarbazone conjugates were synthesized and evaluated against MCF-7 and MDA-MB-231 cell lines. Antiproliferative activities of the synthesized conjugates revealed an optimum combination of longer alkyl chain length as spacer and a halogen-substituent on the isatin ring as a prerequisite for good activity. The compound $6 \mathrm{~g}$ with an optimum combination of chloro-substituent at C-5 position of isatin ring and a butyl chain length proved to be most active and noncytotoxic with $\mathrm{IC}_{50 \text { s }}$ of 54.25 and $26.12 \mu \mathrm{M}$ against MCF-7 and MDA-MB-231 cell lines, respectively.

\section{INTRODUCTION}

Cancer is responsible for approximately 8.2 million deaths and remains as the most difficult disease to treat worldwide. ${ }^{1}$ Rapidly dividing cells such as breast, skin, and uterine cells are at higher risk of mutations compared with cells which do not divide and thus are more prone to develop cancer. Breast cancer $(\mathrm{BC})$ is one of the most frequently occurring cancers leading to significant morbidity and mortality among women. ${ }^{2}$ An insight into cancer facts and figures for the year 2016-2017 revealed an estimated number of deaths of 41070 through BC among women and men in US. ${ }^{3}$ The situation is worse in India where BC accounts $25-32 \%$ of all cancer cases. According to Indian Council of Medical Research (ICMR) survey report 2016, an estimated new number of cancer patients were 14.5 million in 2016 which will likely to reach around 17.3 million by $2020 .^{4}$

One of the significant approaches for the treatment of $\mathrm{BC}$ comprises the selectively inhibiting the binding of estrogen with estrogen receptors $(\operatorname{ER} \alpha$ and $\operatorname{ER} \beta)$ and resulted in the identification of selective estrogen modulators, SERMs. Estrogen has been reported to play a vital role in the growth and development of mammary glands. Interaction of estrogen with estrogen receptors (ER $\alpha$ and $\operatorname{ER} \beta$ ) stimulates the proliferation of mammary cells. MCF-7 cells, being ER $\alpha$ dependent, are found to be sensitive to SERMs while MDAMB-231 cells which are ER- $\beta$ dependent are characterized by the absence of immune-histochemical expression of estrogen, progesterone, and HER2 receptors. ${ }^{5-8}$ Triarylethylenes derivatives like raloxifene, tamoxifen (TAM), and toremifene are approved SERMs by US Food and Drug Administration (FDA) with significant anti-BC profile. ${ }^{9}$ TAM, an antagonist, is the first-line drug employed for the treatment of BC. However, only $70 \%$ of $\mathrm{ER} \alpha$ cases respond to TAM while $30-40 \%$ patients with adjuvant TAM therapy eventually relapse. ${ }^{10-12}$ Furthermore, TAM has an adverse effect on endometrium causing endometrial cancer while raloxifene causes hot flashes, insomnia, dizziness, and melancholy. ${ }^{13}$

Received: July 2, 2018

Accepted: September 12, 2018

Published: September 27, 2018 
Imidazole and its derivatives are of great interest in medicinal chemistry because of their versatile pharmacological properties such as antibacterial, antifungal, anti-tuberculosis, and anticancer activities. ${ }^{14-17}$ Natural imidazolium halides for example, lepidiline A and lepidiline B, are isolated from the roots of Lepidiummeyenii and showed potent cytotoxic activity against the human cancer cell lines. ${ }^{18}$ Further studies on molecular mechanism confirmed that the imidazolium salt hybrids can induce G1 phase cell cycle arrest and apoptosis in tumor cells. ${ }^{19}$

Another important scaffold isatin possess a wide variety of activities such as anticancer, antidepressant, anticonvulsant, antifungal, anti-HIV, and anti-inflammatory properties. ${ }^{20-25}$ BIBF1120 II, an isatin-based triple angio-kinase inhibitor for the diagnosis of nonsmall cell lung cancer, is in phase III clinical trials. ${ }^{26}$ Sunitinib III (Sutent) is another isatin based scaffold approved recently by FDA for treating gastrointestinal stromal tumors and advanced renal cell carcinoma. ${ }^{27}$

A recent report from our laboratory has shown the synthesis and antiproliferative evaluation of a series of $1 \mathrm{H}$-1,2,3-triazole linked ospemifene-isatin conjugates against MCF-7 and MDA-MB-231 cell lines. ${ }^{28}$ In continuation, ${ }^{29}$ the present work comprises the synthesis, antiproliferative evaluation, and docking studies of $1 \mathrm{H}-1,2,3$-triazole tethered imidazole-isatin and imidazole-isatin-thiosemicarbazone conjugates against MCF-7 and MDA-MB-231 cell lines. The promising scaffolds were also evaluated to inspect their cytotoxicity against normal HEK-293 (human embryonic kidney) cell line.

\section{RESULT AND DISCUSSION}

Synthetic methodology involved sodium hydride-promoted $\mathrm{N}$ alkylation of $\mathbf{1 a - c}$ and subsequent treatment with sodium azide afforded the $N$-alkylazido-isatins $3 \mathbf{a}-\mathbf{c}$ (Scheme 1). Another precursor viz. 2-methyl-5-nitro-1-(prop-2-yn-1-yl)$1 \mathrm{H}$-imidazole 5 was prepared via $\mathrm{K}_{2} \mathrm{CO}_{3}$-promoted $\mathrm{N}$ propargylation of $\mathbf{4}$ in anhyd DMF.

\section{Scheme 1. Synthesis of Substituted N-Alkyl-azido-isatins}

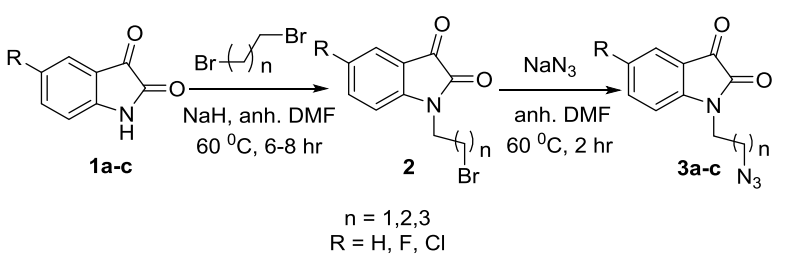

The target $1 H$-1,2,3-triazole-tethered-2-methyl-5-nitroimidazole-isatin conjugates $\mathbf{6 a}-\mathbf{l}$ were obtained via $\mathrm{Cu}$-promoted 1,3-cycloaddition reaction between appropriate precursors' 5 and 3 as depicted in Scheme 2.

The synthesized conjugates $\mathbf{6 a}-\mathbf{l}$ were further reacted with thiosemicarbazide in refluxing ethanol to yield the corresponding 2-methyl-5-nitroimidazole-isatin-thiosemicarbazones $7 \mathbf{a}-1$. The structure assigned to the synthesized conjugates was based on spectral data and analytical evidence. Compound 6b, for example, characterized as 1-(3-(4-((2-methyl-5nitro$1 H$-imidazole-1-yl)-1H-1,2,3-triazol-1-yl)propyl)indoline-2,3dione showed a molecular ion peak at $m / z 396.1389[\mathrm{M}+\mathrm{H}]^{+}$ in its high-resolution mass spectrum (HRMS). The salient features of its proton nuclear magnetic resonance ( ${ }^{1} \mathrm{H}$ NMR) spectrum encompassed the appearance of distinguishing peaks at $\delta 2.17,3.72,4.46$, and 5.34 conforming to different methylenes and a singlet at $\delta 2.39$ corresponding to methyl at $\mathrm{C}-2$ position of the imidazole ring. Its carbon nuclear magnetic resonance $\left({ }^{13} \mathrm{C} \mathrm{NMR}\right)$ spectrum, apart from requisite number of carbons, exhibited characteristic absorptions corresponding to isatin carbonyls at $\delta 158.7$ and 183.7, further corroborating the assigned structure.

The synthesized library of 2-methyl-5-nitroimidazole-isatin and 2-methyl-5-nitroimidazole-isatin-thiosemicarbazones were assessed for their antiproliferative profile against MCF-7 $(\mathrm{ER} \alpha)$ and MDA-MB-231 (ER $\beta)$ human BC cell lines using an MTT assay. The growth inhibitions of synthesized compounds against MCF-7 and MDA-MB-231 cells at variable concentrations have been summarized in Figure 1 using plumbagin as the positive control. $\mathrm{IC}_{50}$ value, which is the concentration required to inhibit $50 \%$ of cell viability by the test compounds, has been summarized in Table 1 .

As evident, the activities of synthesized conjugates were found to depend upon the nature of substituent at C-5 position of isatin ring, the alkyl chain length introduced as spacer, and the nature of functionality at $\mathrm{C}-2$ position of isatin ring. Analyzing structure-activity relationship (SAR) among conjugates $\mathbf{6 a}-\mathbf{d}(\mathrm{R}=\mathrm{H})$; revealed that the compounds were more active against MCF-7 than MDA-MB-231 cells at higher concentrations. Among conjugates $6 \mathrm{e}-\mathrm{h}(\mathrm{R}=\mathrm{Cl})$; the activity tends to increase with the increase in chain length, with compounds being more cytotoxic against MDA-MB-231 than MCF-7 cell lines. The conjugate $6 \mathrm{~g}(\mathrm{R}=\mathrm{Cl}, n=3)$; exhibited comparable $\mathrm{IC}_{50}$ value to that of standard drug TAM against MCF-7 while $\sim 3$ times more activity has been observed against MDA-MB-231 cell line. Similarly, 6h $(\mathrm{R}=\mathrm{Cl}, n=4)$ was found to be $\sim 2$ times more potent in MCF-7 and $\sim 5$ times in MDA-MB-231 compared with TAM (Figure 1).

Similar effects were observed by replacing chloro with fluoro at C-5 position of isatin ring. The conjugate $6 \mathbf{k}(n=3)$ and $7 \mathbf{l}$ $(n=4)$ showed comparable activities to TAM against both cell lines (Figure 2). The carbonyl group at C-3 position of isatin ring was converted to the corresponding thiosemicarbazone with a view of enhancing their cytotoxic activities as evidenced by literary rationale. ${ }^{30}$ The resulting isatin-nitroimidazolethiosemicarbazones were then evaluated against both cell lines viz. MCF-7 and MDA-MB-231. Interestingly, the introduction of thiosemicarbazone functionality improved the activity profiles as evident by $7 \mathrm{~d}$ which exhibited an $\mathrm{IC}_{50}$ value of $\sim 70 \mu \mathrm{M}$ against both cell lines while the parent compounds 6a-d were inactive (Figure 1).

Furthermore, Cl-substituted-isatin-imidazole-thiosemicarbazones were found to be more active against MDA-MB-231 cells than in ER + MCF-7 cells but did not cause 50\% growth inhibition in either of the cell line (Figure 1). Especially compounds $7 \mathbf{e}-7 \mathbf{g}$ (Figure 1) inhibited growth of more than $30 \%$ of cells at low concentrations $(1,5$ and $10 \mu \mathrm{M})$, whereas less than $50 \%$ cell death was observed in MCF-7 cells even at higher concentrations. The compounds, $7 \mathbf{b}-\mathbf{7 d}$ showed similar patterns indicating that these compounds are not necessarily reliant on the presence of the ER. A further trend has also been observed where $50 \mu \mathrm{M}$ concentrations proved to be most effective in inhibiting cell growth, which could be attributed to the development of resistance at higher concentrations.

Because 6g, 6h, 6l, and 7d showed significant growth inhibition in both MCF-7 and MDA-MB-231 cells, we further tested them on a normal cell line HEK-293 to confirm their potential as anticancer agents. The percentage growth inhibition of the promising compounds along with their $\mathrm{IC}_{50}$ 
Scheme 2. Synthesis of 2-Methyl-5-nitroimidazole-Isatin Conjugates and 2-Methyl-5-nitroimidazole-IsatinThiosemicarbazones

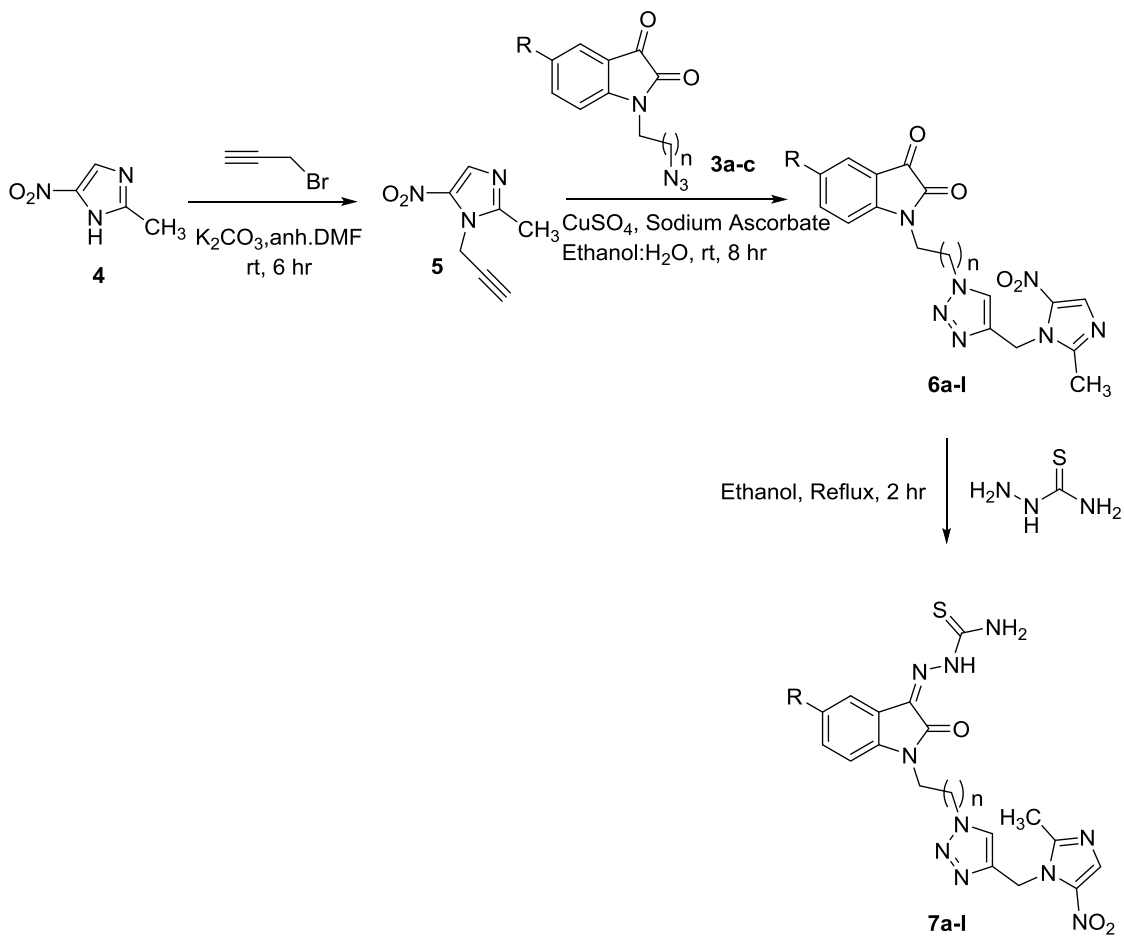

values is provided in Figure 2 and Table 2, respectively. As evident, except for $\mathbf{6 h}$, the other three tested compounds exhibited $\mathrm{IC}_{50}$ values greater than $100 \mu \mathrm{M}$, indicative of the fact this molecular framework holds plausible promise for the design of new antiproliferative agents against BC.

\section{MOLECULAR DOCKING STUDIES}

Molecular docking of the active ligands in the binding site of insulin growth factor-1 (IGF-1) was performed to determine the crucial binding interactions responsible for the inhibitory effect observed. IGF-1 is a transmembrane tyrosine kinase which plays a significant role in the development and function of many tissues, including the mammary gland. It is implicated in malignant $\mathrm{BC}$ as it is over-expressed in tumors. It is responsible for mediating cell-proliferation and providing protection against cell apoptosis. The signaling of the IGF pathway has been noted to directly affect the propensity for invasion and metastasis by influencing tumor cell motility and adhesion. $^{31}$

The native ligand in the crystal structure of IGF-1 (PDB ID: $1 \mathrm{JQH}$ ) was an adenylyl imidodiphosphate which inhibited the receptor by binding to the kinase domain. The binding interaction profile of the ligand-protein complex largely comprised hydrogen bonds with residues Ser26, Lys22, Glu97, Met99, and Lys50, as well as the formation of a water bridge with Lys22. Compound 6h (Figure 3) was measured to be the most potent inhibitor against MCF-7 and MDA-MB-231, $\mathrm{IC}_{50}=20.76$ and $16.06 \mu \mathrm{M}$, respectively (lowest docking score $=-7.8 \mathrm{kcal} / \mathrm{mol}$, Table 3 ). The binding landscape of the ligand-receptor complex incorporates hydrophobic interactions between residue Val30 with the carbons of six-membered ring of the indoline moiety (bond distance $=3.88$ and $3.85 \AA$ ) as well as residue Val80 and alkyl linker (bond distance $=3.80 \AA$ ).
This is accompanied by two hydrogen bonds between the hydrogen bond donors Lys50 and Met99 with the $\mathrm{sp}^{2}$ hybridized nitrogen of the imidazole and carbonyl of the indoline-2,3-dione, respectively (bond distance $=2.00$ and 1.90 $\AA$ A bond angle $=157.21^{\circ}$ and $157.05^{\circ}$, respectively). A salt bridge facilitates an electron shuttle between the $\mathrm{sp}^{3}$-hybridized nitrogen of the triazole which becomes protonated and residue Asp 165, bond distance $=4.12 \AA$ ). The interaction network of the second most active inhibitor, compound $6 \mathrm{~g}$, is similar to compound 6h (Figure 3); however, it comprises fewer hydrophobic interactions, which is compensated by an increased number of hydrogen bonds. The two van der Waals interactions exist between residue Val80 with the alkyl linker and Asp103 with the methyl group of the imidazole ring (bond distance $=3.78 \AA$ ).

Four distinct hydrogen bonds which confer inhibition occur between the proton donor residues Ser26 and the oxygen of the nitro functional group, Lys50, and the $\mathrm{sp}^{2}$-hybridized nitrogen of the triazole ring, Met99, and the oxygen of the indoline moiety as well as the proton acceptor residue Asp165 and the $\mathrm{sp}^{2}$-hybridized nitrogen of the triazole ring (bond distance $=3.23,2.27,1.89$ and $2.39 \AA$; bond angle $=136.17^{\circ}$, $138.48^{\circ}, 154.26^{\circ}$ and $125.62^{\circ}$, respectively). A salt bridge exists between the $\mathrm{sp}^{3}$-hybridized nitrogen of the triazole which becomes protonated and residue Asp165, (bond distance = $4.32 \AA$ ) like compound $\mathbf{6 h}$.

Two compounds were identified as potential candidates as anti-BC agents in both the MCF-7 and MDA-MB-231 celllines with the aid of further derivatisation, these include conjugates 61 and $7 \mathbf{d}$. The complexes of these two ligands share a similar binding profile with contributions specifically from hydrophobic interactions and hydrogen bonds. There are five notable van der Waals interactions between: Leu22/ Val30/Ala48/Met99 and the six-membered ring of the indoline moiety, as well as Phe166 with the methyl group of 

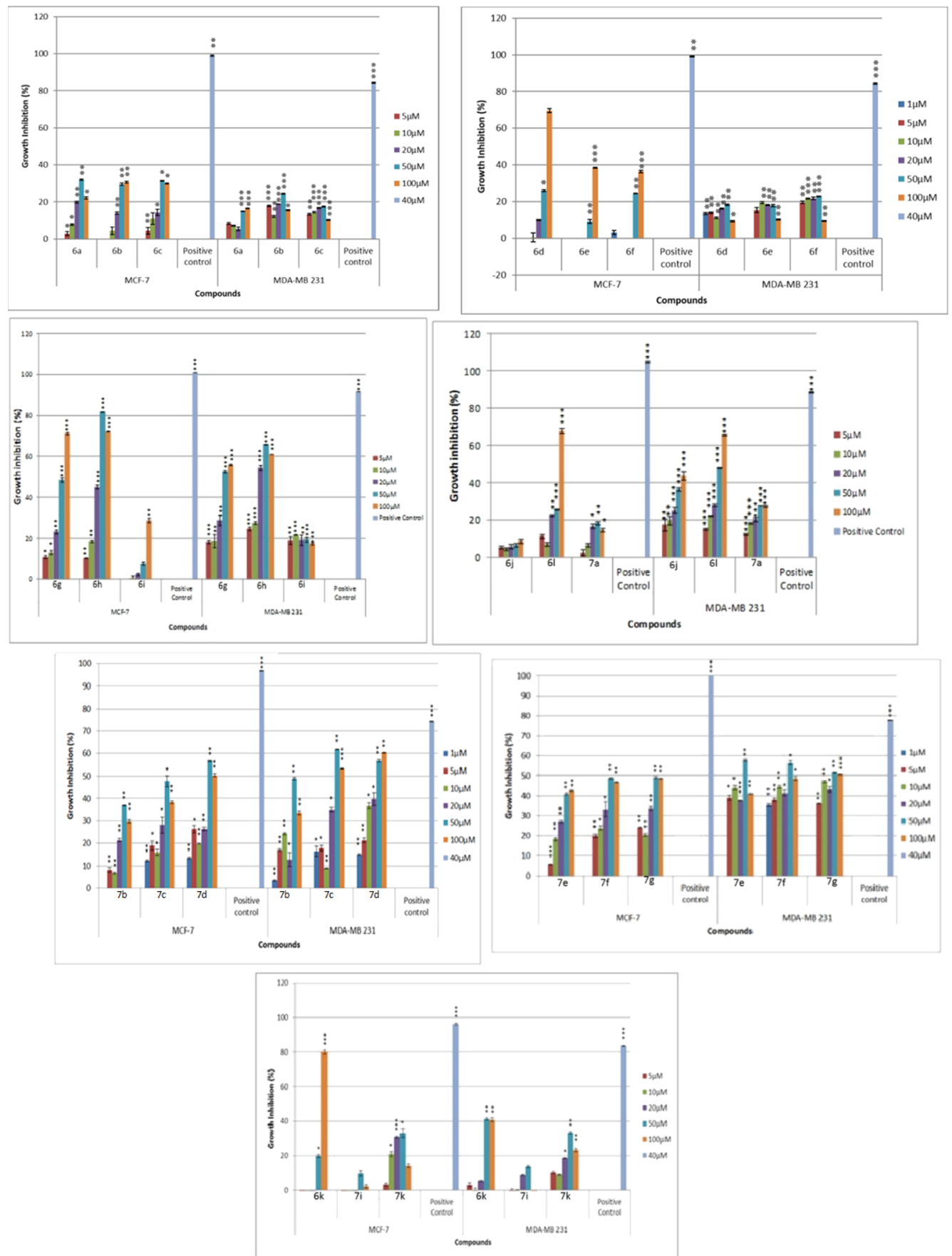

Figure 1. Representative graph comparing the percentage growth inhibition of MCF-7 and MDA-MB 231 cells at selected concentrations of test compounds 6a, 6b, 6c, 6d, 6e, 6f, 6g, 6h, 6i, 6j, 61, 7a, 7b, 7c, 7d, 7e, 7f, 7g, 6k, 7i, and 7k. Plumbagin (40 $\mu \mathrm{M})$ was used as a positive control. Data are mean \pm standard deviation S.D. $(n=3)$ from raw data, where $*_{p}<0.05, *_{p}<0.01$ and $* * * p<0.001$ significant difference to untreated control.

the imidazole ring (bond distance $=3.99,3.71 / 3.87,3.97$ and $3.90 \AA$, respectively). A well-defined network of hydrogen bonds is observed between hydrogen bond donors: Ser26/ Lys176 with oxygen of the nitroimidazole moiety, Lys50/ Gly167 with nitrogen of the imidazole ring, and Met99 with the carbonyl oxygen adjacent to the amine of the indoline pharmacophore (bond distance $=2.03,2.03,2.06,3.07$, and $2.62 \AA$; bond angle $=163.38^{\circ}, 173.54^{\circ}, 158.68^{\circ}, 130.33^{\circ}$, and $145.78^{\circ}$, respectively).

Compound $\mathbf{7 d}$ exhibited an additional hydrogen bond interaction between the donor Leu22 and the terminal amine of the hydrazinecarbothioamide (bond distance $=1.95$ and 2.15; bond angle $=146.25$ and 139.07). A pertinent difference in the binding profile of compound 61 over compound $7 \mathbf{d}$ in the form of a salt bridge, which facilitates the transfer of electrons between Asp165 and the $\mathrm{sp}^{3}$-hybridized nitrogen of the triazole, may be directly responsible for the improved inhibition highlighted against the MDA-MB-231 cell-line $\left(\mathrm{IC}_{50}\right.$ $=56.18(61)$ and $70.40(7 \mathrm{~d}) \mu \mathrm{M})$.

It is further surmised that the length of the alkyl chain can be no shorter that four/five carbons long, if any shorter the salt bridge may be disrupted through space by the electron- 
Table 1. $\mathrm{IC}_{50}$ Values of Synthesized Conjugates against MCF-7 and MDA-MB-231 Cell Lines along with \% Yield

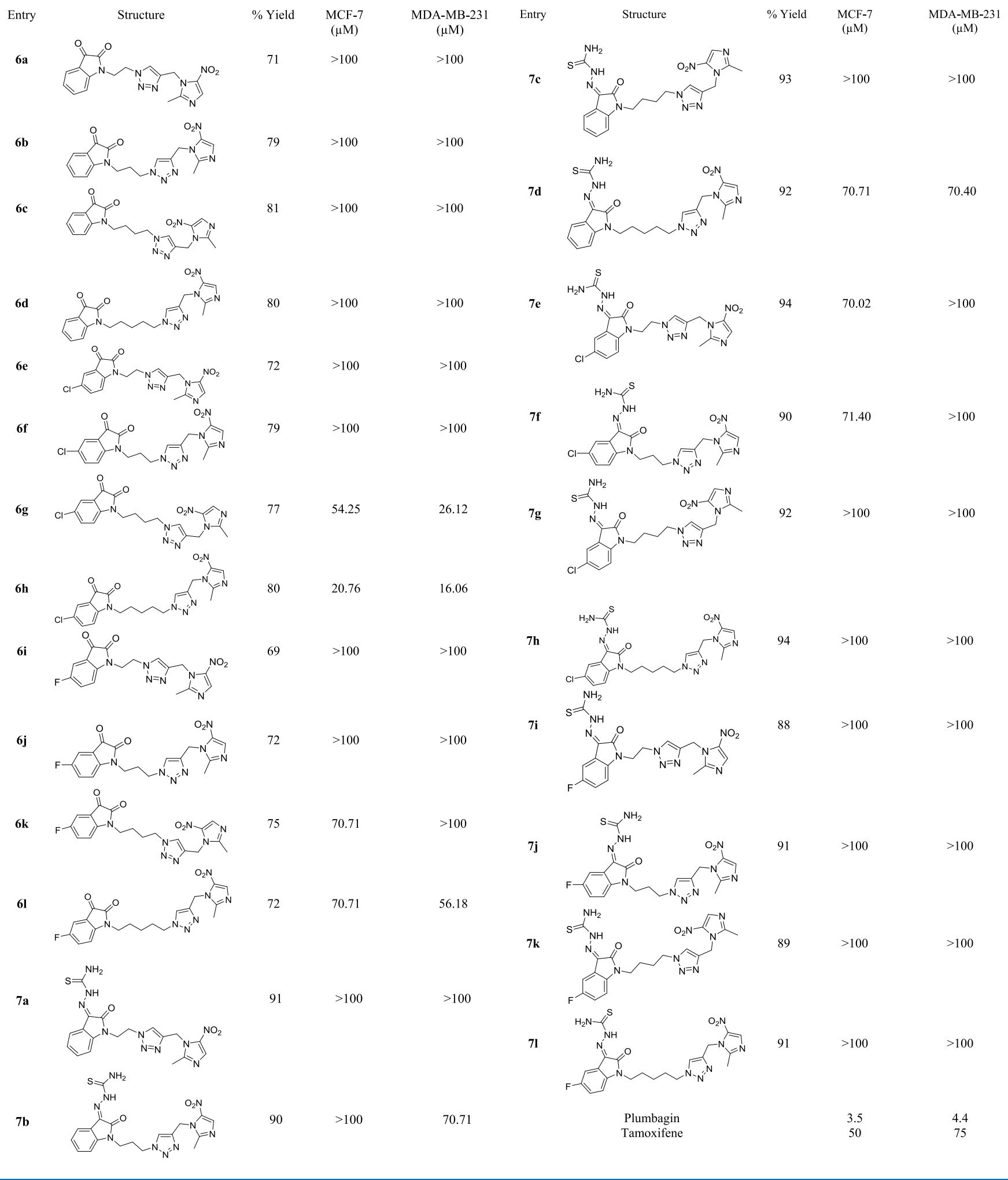

withdrawing effect of chloride and nitro groups. This effect is negated in the imidazole-isatin-thiosemicarbazones, whereby the presence of the hydrazinecarbothioamide has an electrondonating effect to compensate thus improving the inhibitory activity of alkyl chain lengths of two/three carbons.

Table 4 highlights the physical properties of the designed inhibitors. It is evident that in order for the isatin conjugate to be active against both MCF-7 and MDA-MB-231 cell lines, the ligand must maintain an overall more hydrophobic nature (TPSA $=131.73 \AA^{2}$ for both compounds $\mathbf{6 g}$ and $\mathbf{6 h}$ ). The log $P$ further supports this, as compounds $6 \mathrm{~g}, 6 \mathrm{~h}$, and 61 have a higher partition co-efficient which indicates improved lipophilicity. This study has revealed high value scaffolds in the development of anti-BC chemotherapies capable of multitargeting different types of BCs. This work provides a platform on to which further development of the selective inhibitors can 


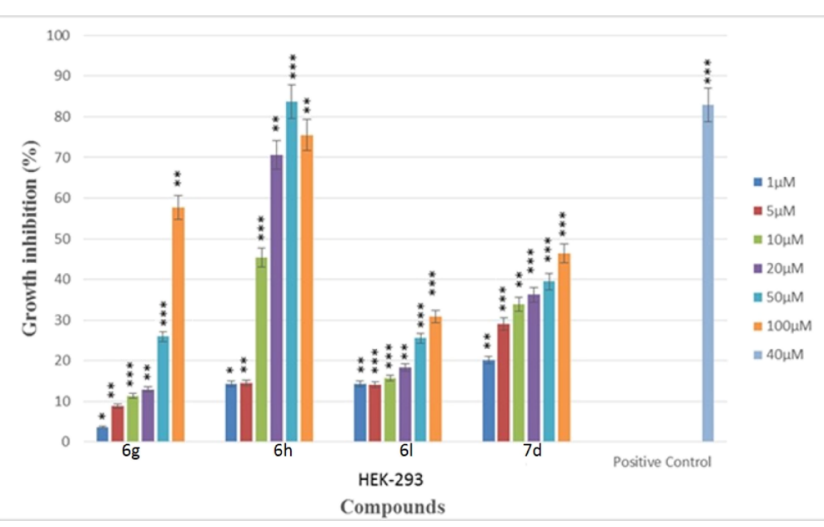

Figure 2. Representative graph showing percentage growth inhibition of HEK-293 cells at selected concentrations of test compounds $\mathbf{6 g}$, 6h, $\mathbf{6 l}$, and $7 \mathbf{d}$. Plumbagin $(40 \mu \mathrm{M})$ was used as a positive control. Data are mean \pm standard deviation S.D. $(n=3)$ from raw data, where $* p<0.05, * * p<0.01$ and $* * * p<0.001$ significant difference to untreated control.

Table 2. $\mathrm{IC}_{50}$ Values of Synthesized Conjugates against HEK-293 Cell Lines

$\begin{array}{cc}\text { entry } & \text { HEK-293 }(\mu \mathrm{M}) \\ \mathbf{6 g} & >100 \\ \mathbf{6 h} & 12.11 \\ \mathbf{6 I} & >100 \\ \mathbf{7 d} & >100\end{array}$

be pursued as selectivity toward a triple negative BC cell-line is rarely observed with imidazole derivatives.

On the basis of the above evaluation studies, the developed SAR can be summarized as elucidated in Figure 4.

\section{CONCLUSION}

In conclusion, a series of $1 \mathrm{H}$-1,2,3-triazole tethered imidazoleisatin conjugates and imidazole-isatin-thiosemicarbazones were synthesized and evaluated against MCF-7 and MDAMB-231 cell lines. Although the compounds were not as active
Table 3. Docking of the Most Active Compounds in IGF-1 Receptor

\begin{tabular}{lccc} 
ligand identifier & docking score $/(\mathrm{kcal} / \mathrm{mol})$ & rmsd i.b. & rmsd u.b. \\
\hline $\mathbf{6 g}$ & -7.3 & 1.968 & 2.325 \\
$\mathbf{6 h}$ & -7.8 & 2.452 & 3.354 \\
$\mathbf{6 l}$ & -7.6 & 2.790 & 3.639 \\
$7 \mathbf{b}$ & -7.2 & 3.738 & 8.021 \\
$\mathbf{7 d}$ & -6.7 & 3.006 & 4.077 \\
native ligand & -7.2 & 1.721 & 2.587 \\
\hline
\end{tabular}

as the standard compound plumbagin, some of the conjugates showed comparable activity to that of TAM. The conjugate $6 \mathbf{h}$, with an optimum combination of pentyl chain length as spacer and a chloro-substituent on the isatin ring, exhibited $\mathrm{IC}_{50 \mathrm{~s}}$ of 20.76 and $16.06 \mu \mathrm{M}$ against MCF-7 and MDA-MB-231 cell lines, respectively, but also seemed to inhibit the growth of the control cells HEK-293 with an $\mathrm{IC}_{50}$ value of $12.11 \mu \mathrm{M}$. However, compounds $\mathbf{6 g}$, 6l, and $7 \mathrm{~d}$ with promising $\mathrm{IC}_{50 \mathrm{~s}}$ against the MCF-7 and MDA-MB-231 cell lines proved to be noncytotoxic to HEK-293 and can be taken further as possible anti-BC agents.

\section{EXPERIMENTAL SECTION}

General Information. ${ }^{1} \mathrm{H}$ NMR spectra were recorded in $\mathrm{CDCl}_{3}$ and DMSO- $d_{6}$ with a JEOL $400(400 \mathrm{MHz})$ and Bruker $500(500 \mathrm{MHz})$ spectrometer using TMS as an internal standard. Chemical shift values are expressed as parts per million downfield from TMS and $J$ values are expressed in hertz. Splitting patterns in the obtained NMR's are indicated as $\mathrm{s}$ : singlet, $\mathrm{d}$ : doublet, $\mathrm{t}$ : triplet, $\mathrm{m}$ : multiplet, $\mathrm{dd}$ : double doublet, ddd: doublet of a doublet of a doublet, and br: broad peak. ${ }^{13} \mathrm{C}$ NMR spectra were recorded on a JEOL 400 (100 $\mathrm{MHz})$ and Bruker $500(125 \mathrm{MHz})$ spectrometer in $\mathrm{CDCl}_{3}$ and DMSO- $d_{6}$ using TMS as an internal standard. HRMS were recorded on a Bruker-micrOTOF-Q II spectrometer.

Materials and Methods. The cytotoxicity studies of the synthesized conjugates viz. $6 \mathbf{a}-\mathbf{1}$ and $7 \mathbf{a}-\mathbf{l}$ was tested on two different $\mathrm{BC}$ cell lines, namely, ER positive (ER+) MCF-7 cells and triple negative MDA-MB-231 (ER-) using MTT (3-(4,5-

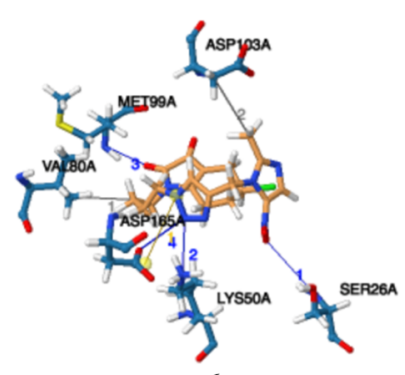

$6 \mathrm{~g}$

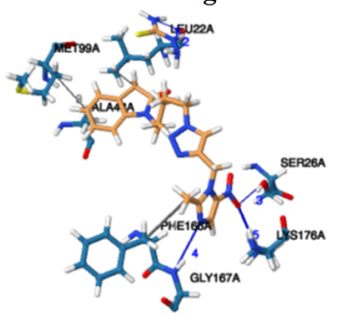

7d

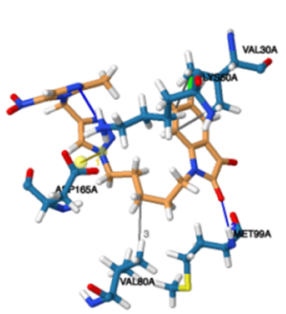

6h

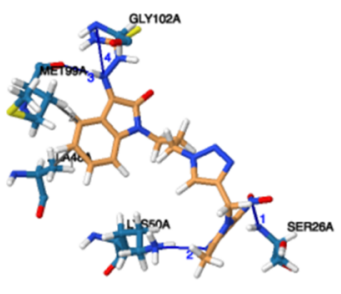

$7 b$

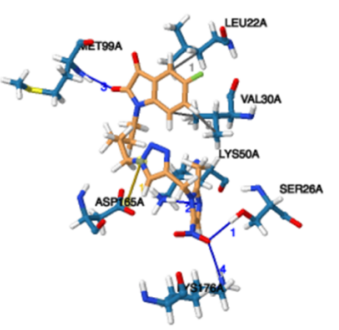

6I

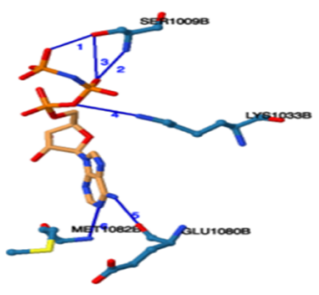

Native Ligand

Figure 3. Three-dimensional illustration of docked ligands in IGF-1 receptor kinase domain. 
Table 4. Physical Properties of the Docked Compounds

\begin{tabular}{|c|c|c|c|c|c|c|c|}
\hline \multirow[b]{2}{*}{ compound ID } & \multirow[b]{2}{*}{$\log P$} & \multirow[b]{2}{*}{ TPSA $/ \AA^{2}$} & \multirow[b]{2}{*}{ rotatable bonds } & \multirow[b]{2}{*}{ molecular weight $/ \mathrm{g} \mathrm{mol}^{-1}$} & \multicolumn{3}{|c|}{ pharmacophore features } \\
\hline & & & & & acceptors & donors & ionizable groups/charge \\
\hline $6 \mathrm{~g}$ & 1.55 & 131.73 & 8 & 443.84 & 7 & 0 & 0 \\
\hline $6 \mathrm{~h}$ & 1.98 & 131.73 & 9 & 457.87 & 7 & 0 & 0 \\
\hline 61 & 1.77 & 131.73 & 9 & 441.42 & 8 & 0 & 0 \\
\hline $7 \mathbf{b}$ & 0.82 & 197.16 & 8 & 454.47 & 7 & 2 & $1 /+$ \\
\hline $7 d$ & 1.50 & 197.16 & 11 & 496.55 & 7 & 2 & $1 /+$ \\
\hline native ligand & -7.21 & 307.09 & 8 & 514.26 & 18 & 11 & $3 /-$ \\
\hline
\end{tabular}

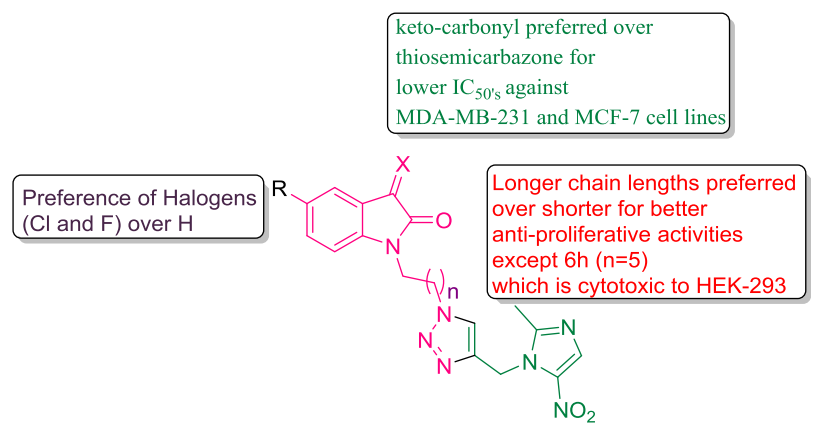

Figure 4. Generalized SAR of the synthesized compounds against BC.

dimethylthiazol-z-yl)-2,5-diphenyltetrazolium bromide) assay. $^{28}$

Cell Culturing. MCF-7 cells were cultured in Dulbecco's media Eagle's medium (DMEM) media with $10 \%$ fetal bovine serum (FBS), and $1 \%$ penicillin-streptomycin and MDA-MB 231 cells were cultured in DMEM supplemented with 5\% FBS and $1 \%$ penicillin-streptomycin, both incubated at $37^{\circ} \mathrm{C}$ and $5 \%$ carbon dioxide.

MTT Assay. Cells were seeded in 96-well plates at a density of 5000 cells per well in triplicate in media. After $24 \mathrm{~h}$, the test compounds, diluted in complete DMEM were added to each well. Cells were treated with a range of different concentrations of drug $(1,5,10,20,50,100 \mu \mathrm{M})$ for $24 \mathrm{~h}$ at $37{ }^{\circ} \mathrm{C}$ and $5 \%$ carbon dioxide. ${ }^{28}$ Subsequently, sterile $5 \mu \mathrm{L}$ of $5 \mathrm{mg} / \mathrm{mL}$ MTT (Sigma-Aldrich) dissolved in phosphate-buffered saline was added to each well and incubated with cells for $2 \mathrm{~h}$. Solubilization solution (10\% sodium dodecyl sulfate, $10 \mathrm{mM}$ $\mathrm{HCl}$ ) of equal volume to the wells was then added to each well, which was incubated with cells for $16 \mathrm{~h}$ at $37^{\circ} \mathrm{C}$. The optical density of each well was read at $570 \mathrm{~nm}$ using a microtiter plate reader (Thermo Fisher Scientific Multiskan GO Microplate Reader, SkanIt software). ${ }^{32}$

Statistical Analysis. The statistical analysis was performed using Excel, and $\mathrm{IC}_{50}$ values were estimated using Graph pad Prism5 software (Hearne Scientific Software). The experiments were performed in duplicate and the statistical significance was calculated using Student's $t$-test. ${ }^{29 a}$ A $p$-value of less than 0.05 was used to estimate the significance of the observations. A Z-factor was calculated for each 96-well plate and assays having $\mathrm{Z}$-factor above $>0.5$ were included in the statistical analysis. ${ }^{33}$

Docking Methods. The X-ray crystal structures of the IGF-1 receptor (PDB ID: 1JQH) was obtained from the RCSB Protein Data Bank (http://www.rcsb.org/pdb/home/home. do). Using the UCSF Chimera package the ligand and receptor complexes were prepared for docking. ${ }^{34}$ Chem3D Ultra was used to construct a three-dimensional (3D) structure of the native ligand and most active isatin conjugates. The $3 \mathrm{D}$ structure of the compounds was further optimized using the force field, MMFF94s in the Avogadro package (V 1.2.0). AutoDock Tools (V 1.5.6) was used to establish the grid box parameters. All nonpolar hydrogens were merged, Gasteiger partial atomic charges added, and rotatable bonds assigned. The grid box of the complex had a grid spacing of $0.375 \AA$. The parameter of the grid points are given in Table S1 (Supporting Information). Autodock Vina was used to perform the docking of each ligand into the IGF-1 receptor in triplicate. ${ }^{35}$ The docking systems were validated by redocking the ligand of the protein crystal structures into the binding site. The proteinligand interaction profiler was used to analyze the nonpolar interactions between the protein and ligand in complex. ${ }^{36}$

\section{ASSOCIATED CONTENT}

\section{Supporting Information}

The Supporting Information is available free of charge on the ACS Publications website at DOI: 10.1021/acsomega.8b01513.

${ }^{1} \mathrm{H}$ and ${ }^{13} \mathrm{C}$ NMR data of all of the synthesized conjugates along with scanned $\left({ }^{1} \mathrm{H},{ }^{13} \mathrm{C}\right.$, DEPT, $\left.\mathrm{D}_{2} \mathrm{O}\right)$ NMR spectra for representative compounds viz. $\mathbf{6 a}, \mathbf{6 b}$, 6e, 6f, 6h, 6k, 6l, 7b, 7e, 7f, 7i, 7k (PDF)

\section{AUTHOR INFORMATION}

\section{Corresponding Author}

*E-mail: vipan_org@yahoo.com (V.K.).

ORCID

Vipan Kumar: 0000-0002-6164-7161

Notes

The authors declare no competing financial interest.

\section{ACKNOWLEDGMENTS}

V.K. acknowledges the Council of Scientific and Industrial Research (CSIR), New Delhi (grant no. 02IJ0293)/17/EMRI), for providing financial assistance. P.S. would like to thank the National Research Foundation of South Africa for their support in facilitating our research (UID: 99563). We would also like to thank the Centre for High Performance Computing based in Cape Town for access to computational resources.

\section{ABBREVIATION}

$\mathrm{BC}$, breast cancer; ER, estrogen receptor; TAM, tamoxifene; SAR, structure activity relationship; IGF-1, insulin growth factor-1; DMEM, Dulbecco's media Eagle's medium

\section{REFERENCES}

(1) DeSantis, C.; Ma, J.; Bryan, L.; Jemal, A. Breast cancer statistics, 2013. Ca-Cancer J. Clin. 2014, 64, 52-62.

(2) DeSantis, C. E.; Fedewa, S. A.; Sauer, A. G.; Kramer, J. L.; Smith, R. A.; Jemal, A. Breast cancer statistics, 2015: Convergence of 
incidence rates between black and white women. CA-Cancer J. Clin. 2016, 66, 31-42.

(3) Cancer Fact and Figure American Cancer Society. https://www. cancer.org/research/cancer-facts-statistics/all-cancer-facts-figures/ cancer-factsfigures-2017.html, 2017, pp 1-71.

(4) Health Care Global Enterprises Ltd. Annual Report On Cancer 2016-2017. http://icmr.nic.in/icmrsql/archive/2016/7.pdf.

(5) Haldosén, L.-A.; Zhao, C.; Dahlman-Wright, K. Estrogen Receptor beta in Breast Cancer. Mol. Cell. Endocrinol. 2014, 382, 665-672.

(6) Deroo, B. J.; Korach, K. S. Estrogen receptors and human disease. J. Clin. Invest. 2006, 116, 561-570.

(7) Magarian, R. A.; Overacre, L. B.; Singh, S.; Meyer, K. L. The medicinal chemistry of nonsteroidalantiestrogens: a review. Curr. Med. Chem. 1994, 1, 61-104.

(8) Mitlak, B. H.; Cohen, F. J. Selective Estrogen Receptor Modulators. Drugs 1999, 57, 653-663.

(9) Descôteaux, C.; Leblanc, V.; Bélanger, G.; Parent, S.; Asselin, É.; Bérubé, G. Improved synthesis of unique estradiol-linked platinum(II) complexes showing potent cytocidal activity and affinity for the estrogen receptor alpha and beta. Steroids 2008, 73, 1077-1089.

(10) Adsule, S.; Banerjee, S.; Ahmed, F.; Padhye, S.; Sarkar, F. H. Hybrid anticancer agents: Isothiocyanate-progesterone conjugates as chemotherapeutic agents and insights into their cytotoxicities. Bioorg. Med. Chem. Lett. 2010, 20, 1247-1251.

(11) Ellmén, J.; Hakulinen, P.; Partanen, A.; Hayes, D. F. Estrogenic effects of toremifene and tamoxifen in postmenopausal breast cancer patients. Breast Cancer Res. Treat. 2003, 82, 103-111.

(12) Taras, T. L.; Wurz, G. T.; DeGregorio, M. W. In vitro and in vivo biologic effects of Ospemifene (FC-1271a) in breast cancer. J. Steroid Bio che. Mol. Biol. 2001, 77, 271-279.

(13) Kaur, G.; Mahajan, M. P.; Pandey, M. K.; Singh, P.; Ramisetti, S. R.; Sharma, A. K. Design, synthesis and evaluation of Ospemifene analogs as anti-breast cancer agents. Eur. J. Med. Chem. 2014, 86, 211-218.

(14) Jain, A. K.; Ravichandran, V.; Sisodiya, M.; Agrawal, R. K. Synthesis and antibacterial evaluation of 2-substituted-4,5-diphenylN-alkyl imidazole derivatives. Asian Pac. J. Trop. Med. 2010, 3, 471474.

(15) Hu, X. L.; Xu, Z.; Liu, M. L.; Feng, L. S.; Zhang, G. D. Recent Developments of Coumarin Hybrids as Anti-fungal Agents. Curr. Top. Med. Chem. 2017, 17, 3219-3231.

(16) Pandey, J.; Tiwari, V. K.; Verma, S. S.; Chaturvedi, V.; Bhatnagar, S.; Sinha, S.; Gaikwad, A. N.; Tripathi, R. P. Synthesis and antitubercular screening of imidazole derivatives it. Eur. J. Med. Chem. 2009, 44, 3350-3355.

(17) Bistrovic, A.; Krstulovic, L.; Harej, A.; Grbcic, P.; Sedic, M.; Kostrun, S.; Pavelic, S. K.; Bajic, M.; Raic-Malic, S. Design, synthesis and biological evaluation of novel benzimidazoleamidines as potent multi-target inhibitors for the treatment of non-small cell lung cancer. Eur. J. Med. Chem. 2018, 143, 1616-1634.

(18) Cui, B.; Zheng, B. L.; He, K.; Zheng, Q. Y. Imidazole Alkaloids from Lepidiummeyenii. J. Nat. Prod. 2003, 66, 1101-1103.

(19) Zeng, X.; Yang, X.; Zhang, Y.; Qing, C.; Zhang, H. Synthesis and antitumor activity of 1-mesityl-3-(2-naphthoylmethano)-1Himidazolium bromide. Bioorg. Med. Chem. Lett. 2010, 20, 1844-1847.

(20) Ibrahim, H. S.; Abou-Seri, S. M.; Tanc, M.; Elaasser, M. M.; Abdel-Aziz, H. A.; Supuran, C. T. Isatin-pyrazole benzenesulfonamide hybrids potently inhibit tumor-associated carbonic anhydrase isoforms IX and XII. Eur. J. Med. Chem. 2015, 103, 583-593.

(21) Rohini, R.; Reddy, P. M.; Shanker, K.; Kanthaiah, K.; Ravinder, V.; Hu, A. Synthesis of mono, bis-2-(2-arylideneaminophenyl) indole azomethines as potential antimicrobial agents. Arch. Pharmacal Res. 2011, 34, 1077-1084.

(22) Pandeya, S. N.; Smitha, S.; Jyoti, M.; Sridhar, S. K. Biological activities of isatin and its derivatives. Acta Pharm. 2005, 55, 27-46.

(23) Meena, K.; Kumari, S.; Khurana, J. M.; Malik, A.; Sharma, C.; Panwar, H. One pot three component synthesis of spiro [indolo$3,10^{\prime}$-indeno[1,2- b ] quinolin]-2,4,11'-triones as a new class of antifungal and antimicrobial agents. Chin. Chem. Lett. 2017, 28, 136142.

(24) Devale, T. L.; Parikh, J.; Miniyar, P.; Sharma, P.; Shrivastava, B.; Murumkar, P. Dihydropyrimidinone-isatin hybrids as novel nonnucleoside HIV-1 reverse transcriptase inhibitors. Bioorg. Chem. 2017, 70, 256-266.

(25) Akhaja, T. N.; Raval, J. P. Design, synthesis and in vitro evaluation of tetrahydropyrimidine-isatin hybrids as potential antitubercular and antimalarial agents. Chin. Chem. Lett. 2012, 23, $785-788$.

(26) Roth, G. J.; Heckel, A.; Colbatzky, F.; Handschuh, S.; Kley, J.; Lehmann-Lintz, T.; Lotz, R.; Tontsch-Grunt, U.; Walter, R.; Hilberg, F. Design, synthesis, and evaluation of indolinones as triple angiokinase inhibitors and the discovery of a highly specific 6methoxycarbonyl-substituted indolinone (BIBF 1120). J. Med. Chem. 2009, 52, 4466-4480.

(27) Prenen, H.; Cools, J.; Mentens, N.; Folens, C.; Sciot, R.; Schöffski, P. Efficacy of the kinase inhibitor SU11248 against gastrointestinal stromal tumor mutants refractory to imatinib mesylate. Clin. Cancer Res. 2006, 12, 2622-2627.

(28) Kumar, S.; Gu, L.; Palma, G.; Kaur, M.; Singh-Pillay, A.; Singh, P.; Kumar, V. Design, synthesis, anti-proliferative evaluation and docking studies of $1 \mathrm{H}-1,2,3$-triazole tethered ospemifene-isatin conjugates as selective estrogen receptor modulators. New J. Chem. 2018, 42, 3703-3713.

(29) (a) Singh, A.; Saha, S. T.; Perumal, S.; Kaur, M.; Kumar, V. Azide-Alkyne Cycloaddition En Route to $1 \mathrm{H}-1,2,3$-Triazole-Tethered Isatin-Ferrocene, Ferrocenylmethoxy-Isatin, and Isatin-Ferrocenylchalcone Conjugates: Synthesis and Antiproliferative Evaluation. ACS Omega 2018, 3, 1263-1268. (b) Singh, A.; Fong, G.; Liu, J.; Wu, Y.-H.; Chang, K.; Park, W.; Kim, J.; Tam, C.; Cheng, L. W.; Land, K. M.; Kumar, V. Synthesis and Preliminary Antimicrobial Analysis of Isatin-Ferrocene and Isatin-Ferrocenyl Chalcone Conjugates. ACS Omega 2018, 3, 5808-5813. (c) Kumar, S.; Saini, A.; Gut, J.; Rosenthal, P. J.; Raj, R.; Kumar, V. 4-Aminoquinolinechalcone/- N -acetylpyrazoline conjugates: Synthesis and antiplasmodial evaluation. Eur. J. Med. Chem. 2017, 138, 993-1001. (d) Shalini; Viljoen, A.; Kremer, L.; Kumar, V. Alkylated/aminated nitroimidazoles and nitroimidazole-7-chloroquinoline conjugates: Synthesis and anti-mycobacterial evaluation. Bioorg. Med. Chem. Lett. 2018, 28, 1309-1312. (e) Rani, A.; Singh, A.; Gut, J.; Rosenthal, P. J.; Kumar, V. Microwave-promoted facile access to 4-aminoquinolinephthalimides: Synthesis and anti-plasmodial evaluation. Eur. J. Med. Chem. 2018, 143, 150-156.

(30) Ali, A. Q.; Teoh, S. G.; Salhin, A.; Eltayeb, N. E.; Khadeer, A. M. B.; Abdul, A. M. S.A. Synthesis of isatin thiosemicarbazones derivatives: In vitro anti-cancer, DNA binding and cleavage activities. Spectrochim. Acta, Part A 2014, 125, 440-448.

(31) Christopoulos, P. F.; Msaouel, P.; Koutsilieris, M. The role of the insulin-like growth factor- 1 system in breast cancer. Mol. Canc. 2015, 43, 1-14.

(32) Sagar, S.; Esau, L.; Moosa, B.; Khashab, N.; Bajic, V.; Kaur, M. Cytotoxicity and Apoptosis Induced by a Plumbagin Derivative in Estrogen Positive MCF-7 Breast Cancer Cells. Anti-Cancer Agents Med. Chem. 2014, 14, 170-180.

(33) Zhang, J.-H.; Chung, T. D. Y.; Oldenburg, K. R. A Simple Statistical Parameter for Use in Evaluation and Validation of High Throughput Screening Assays. J. Biomol. Screening 1999, 4, 67-73.

(34) Pettersen, E. F.; Goddard, T. D.; Huang, C. C.; Couch, G. S.; Greenblatt, D. M.; Meng, E. C.; Ferrin, T. E. UCSF Chimera?A visualization system for exploratory research and analysis. J. Comput. Chem. 2004, 25, 1605-1612.

(35) Trott, O.; Olson, A. J. AutoDock Vina: improving the speed and accuracy of docking with a new scoring function, efficient optimization and multithreading. J. Comput. Chem. 2010, 31, 455461.

(36) Salentin, S.; Schreiber, S.; Haupt, V. J.; Adasme, M. F.; Schroeder, M. PLIP: fully automated protein-ligand interaction profiler. Nucleic Acids Res. 2015, 43, W443-W447. 